\title{
Pharmaceutical Residues Industry Report
}

\author{
Gisele Ferreira De Souza ${ }^{1 *}$ and Jair Ribeiro Dos Santos Junior ${ }^{2}$ \\ ${ }^{1}$ PhD Medical School Medicine Preventive, University of Sao Paulo FMUSP, Brazil \\ ${ }^{2}$ Scientist Psychology, University State of Maringa UEM, Brazil \\ ${ }^{3}$ Department of Chemistry Education, Federal College of Education Technical Umunze, \\ Anambra State, Nigeria \\ *Corresponding Author: Gisele Ferreira De Souza, PhD Medical School Medicine \\ Preventive, University of Sao Paulo FMUSP, Brazil.
}

\author{
Received: March 30, 2020 \\ Published: May 02, 2020
}

(C) All rights are reserved by Gisele Ferreira

De Souza and Jair Ribeiro Dos Santos

Junior.

\section{Pharmaceutical industry report}

For decades now, pharmaceuticals have been developed and designed to be stable as possible to avoid degradation before reaching their eventual recipient. The next 10 - 15 years could be an era of great progress and growth. In this period, we have the technological, financial and human resources to raise living standards across the world. Good policies that support investment and innovation can further reduce poverty and hunger, make fast-growing cities economically vibrant and socially inclusive, and restore and protect the world's natural environments [1]. Impurities that result from chemical alterations during manufacturing, packaging and storage period are referred to as degradation products [2]. The small amounts of degradation products can affect the drug's safety because of the potential adverse effects in patients. Pharmaceutical drugs can develop the incapability or incapacity to remain within a particular microbiological, chemical, physical, therapeutically and toxicological specification [3].

In silico methods can play an essential role in the identification of alternative chemicals that may contain safer than the other compounds. The research topic was developed by Souza [4], which was quite broad and substantial for public health in our country. The identification of possible health risks to scavengers in work environments of material recycling cooperatives in the metropolitan area of São Paulo related to contact with smog in the form of toxic mold and metal and that could lead to illness from the exposure by the respiratory route or dermal contact of recyclable material, it involved distinct areas this type of exposure to worker. For this purpose, air sample was collected and deposited dust to evaluate occupational exposure to fungi and metals in the studied cooperatives. Special, in silico methods can pay identification of the best alternative chemicals. There is an increased acceptance and interest of the applications of in silico methods for chemical evaluation and regulatory data submission. The alternative safer compounds are rationally designed and used in the packaging or delivery materials, in the manufacturing processes and special additives [5]. In silico, prediction methodologies have been used in detecting mutagenicity and toxicity, and an excellent example is a statistical- based software also known as CRA, CRO is your experience with EDC system(s) such as Merge, DataTrak, Datatrial, Phase Forward, Rave and Quantitative Structure-Activity Relationship (QSAR). The method involves mathematical models that are derived from a testing set of chemicals that were found to be negative and positive in a particular toxicology study $[6,7]$. The model encodes the association between descriptors of the training set and the toxicological response and upon its validation, it can be used to make a prediction.

Impurity Qualification Report includes both the drug product and drug substance impurities that are subjected to severe conditions to indicate the specificity of stability. The opportunity is to harness the expanding capacities of human intelligence and technological progress to improve the lives of the majority of the world's people. The perspectives and theories of the Economic Advisory Panel (EAP) has guided the work of the cooperatives of recyclable materials located in the City of São Paulo, Brazil, and are essential for an understanding of the processes of growth and change, which are at the heart of the challenges and choices [8]. In 2015, Brazil enacted the RDC 53/15 resolution that establishes criteria for the identification, qualification, and reporting of degradation products in packaged drugs [9]. According to Srivastava [10] the provision of the set of regulations applies to all medicinal products with semi-synthetic and synthetic active substances that can be classified as generic, new or branded generics. The goals of the degradation profile studies are to provide evidence of the stability indicating the method and obtain the potential degradation profile. For the forced degradation study to be successful, the sample shall be treated against conditions such as humidity, heating, oxidizing solution, metal ions, basic and acid solutions, among others to ensure the formation of all the predicted degradation products.

The urge to investigate the Geno toxicity of pharmaceutical is increasingly becoming essential in the pharmaceutical industry. These genotoxic impurities (GTIs) are found in drug substances and are as a result of utilizing electrophilic components for making up the molecular structure [11]. Control and identification of the 
impurities pose a challenging task for pharmaceutical companies, and as such, the regulatory agencies have established standards that ensure the limited presence of unavoidable impurities. Purge factor calculation has been used to give a flexible assessment of the potential risks of mutagenic impurities [11].

The methods developed such as in silico drug design, and evaluation has been used in occupational toxicology to manage and understand biological and chemical hazards at work [12,13] SESMA Assistance is one of the foreign aids in Brazil that has expanded its funding in health and agriculture for toxicity research. Our desire is to demonstrate sustainable solutions to improve the management of pharmaceutical wastes marketed by drugstores, clinics and especially, to get the cooperation of the pharmaceutical industry by reducing the costs presented by these pharmaceutical residues with sustainable implementations of concrete and innovative actions such as the use of modern, innovative technology to reduce these pharmaceutical residues [14].

Collaboration in the toxicological evaluation is also on the rise, and the ToxiLatin and BMC Pharmacology and Toxicology have formed a partnership to conduct conferences annually to increase awareness on the advanced approaches in the field of toxicology.

Urgently, is necessary reduce pharmaceutical residues for prevent and less Coronavirus disease (COVID-19) outbreak and lethal doses because the waste pharmaceutical.

\section{Bibliography}

1. Souza GF and BS Sami. "Waste pharmaceutical and Green Pharmaceutical Supply Chain (GPSC)". Paper presented during the International Conference on: Communication, Management and Information Technology (ICCMIT'18), Madrid, Spain, Acceptance letter, Technical Paper (2018).

2. Melo SRd0., et al. "Advice on Degradation Products in Pharmaceuticals: A Toxicological Evaluation". PDA Journal of Pharmaceutical Science and Technology 68.3 (2014): 221-238.

3. Stanimirovic V., et al. "Importance of pharmaco-toxicological evaluation of increased drug impurities and preserving drug quality and patient's safety". Basic and Clinical Pharmacology and Toxicology 107 (2010): 109.

4. Souza GF. "Environmental assessment in the cooperatives of recyclable materials". Doctoral Thesis, Faculdade de Medicina, Universidade de São Paulo; São Paulo, Brazil (2015).

5. Rastogi T., et al. "Designing green derivatives of $\beta$-blocker Metoprolol: A tiered approach for green and sustainable pharmacy and chemistry". Chemosphere 111 (2014): 493-499.

6. Cherkasov A., et al. "QSAR modeling: Where have you been? Where are you going to?" Journal of Medicinal Chemistry 57.12 (2014).
7. Gad SC. "QSAR". In Encyclopedia of Toxicology: Third Edition (2014): 1-9.

8. Souza GF and BS Sami. "Waste pharmaceutical potential environmental risks". International Conference on Communication, Management and Information Technology (ICCMIT'18), Madrid, Spain, Acceptance letter, Technical Paper (2018).

9. Charde MS., et al. "Review: Development of forced degradation studies of drugs". International Journal of Advances in Pharmaceutics 2.3 (2013): 1-6.

10. Srivastava RK. "An updated review: forced degradation study". World Journal of Pharmacy and Pharmaceutical Sciences (2017): 709-726.

11. Kragelj Lapanja N., et al. "Theoretical Purge Factor Determination as a Control Strategy for Potential Mutagenic Impurities in the Synthesis of Drug Substances". Acta Chimica Slovenica 64.1 (2017): 1-14.

12. Occupational Toxicology, Second Edition (2018).

13. Wattenberg EV. "Occupational Toxicology". In Encyclopedia of Toxicology: Third Edition (2014): 643-647.

14. Souza GF, et al. "Occupational exposure to mercury in cooperatives of recyclable materials the metropolitan region of São Paulo". Ciência and Saúde Coletiva (2017).

\section{Assets from publication with us}

- Prompt Acknowledgement after receiving the article

- Thorough Double blinded peer review

- Rapid Publication

- Issue of Publication Certificate

- High visibility of your Published work

Website: https://www.actascientific.com/

Submit Article: https://www.actascientific.com/submission.php Email us: editor@actascientific.com

Contact us: +919182824667 